\title{
Examining the Interrelations Among Knowledge, Interests, and Learning Strategies
}

\author{
Bo Shen \\ Wayne State University \\ Ang Chen \\ University of Maryland-College Park
}

\begin{abstract}
Guided by the Model of Domain Learning (MDL), the study was designed to explore the extent of interrelations among prior knowledge, learning strategies, interests, physical engagement, and learning outcomes in a sixth-grade $(\mathrm{N}=91)$ volleyball unit. Pearson product-moment correlations and a path analysis were conducted for the research purpose. The results showed that students' prior knowledge, learning strategies, and interests were interrelated. Physical engagement and learning outcomes were directly influenced by the interactions among prior knowledge, interests, and learning strategies. The findings in the study indicate that learning in physical education is domain-specific and a progressive process that encompasses both cognitive and affective components.
\end{abstract}

Key words: domain learning, model, learning outcomes

According to cognitive learning theory (Doyle, 1977; Shuell, 1986), learning is an active, constructive, and goal-oriented process mediated by learner thoughts associated with the subject matter. The complex array of learner thoughts can be understood in three related dimensions: prior knowledge, learning strategies, and motivation. These thoughts comprise an interrelated mental network that determines learning in the classroom (Alexander \& Murphy, 1999) and gymnasium (Solmon \& Lee, 1996).

There have been consistent findings that prior knowledge plays a positive role in learning new knowledge. It guides new knowledge representation and organization, provides a basis of association between old and new information, and attaches meaning to all new experiences (Alexander \& Murphy, 1999). In physical education, Silverman, Subramaniam, and Woods (1998) reported that the more knowledge

Shen is with the Department of Kinesiology, Health, and Sports Study, College of Education, Wayne State University, Detroit, MI 48202. Chen is with the Department of Kinesiology, University of Maryland, Room 2312, HHP Building, College Park, MD 20742-2611. 
and skills learners possess prior to learning, the more new knowledge and skills they are likely to acquire.

The influence of prior knowledge on learning may be reflected in learners' application of learning strategies during the learning process. Learning strategies can be defined as mental operations that learners use to solve problems or to enhance achievement (Alexander \& Murphy, 1999). In physical education, learners are expected to be able to determine "which, if any, learning strategies they will employ during practice of movement activities" (Lee, 1997, p. 272). Researchers have shown that learning strategies can improve knowledge and motor skill acquisition (Lee, Landin, \& Carter, 1992).

Choosing and applying appropriate learning strategies require the learner to be an active agent in learning. Learners must be motivated in order to be able to actively search, evaluate, and eventually adopt effective learning strategies (Pintrich, Marx, \& Boyle, 1993). Motivation in this context serves as a primary force that leads the learner to develop useful learning strategies to achieve the learning goal. Among several motivation sources, interest has become one that draws increasing attention among educational researchers, because of its positive implications for curriculum and instruction (Chen \& Ennis, 2004).

Interest-based motivation theory suggests that interest arises as individuals interact with the environment (Hidi, 2000). It is a psychological state that involves focused attention, increased cognitive functioning, persistence, and affective involvement. Researchers have identified two types of interest: individual interest and situational interest. Individual interest is defined as an individual's relatively enduring predisposition of preference to certain objects, events, and activities (Renninger, 2000). Situational interest, on the other hand, is the momentary appealing effect of an activity on an individual in a particular context and at a particular moment (Hidi, 2000). Researchers in education (Hidi, 2000) and physical education (Chen \& Darst, 2001) have shown that interests can attract learners to particular learning tasks, increase engagement time on a task, improve information storage, and enhance achievement.

From an integrated perspective, Alexander, Jetton, and Kulikowich (1995) proposed the Model of Domain Learning (MDL) to delineate and explain the multidimensional interplay of prior knowledge, interests, and learning strategies during learning in a specific content domain. It is postulated that the effect of interrelationships among prior knowledge, interests, and learning strategies should be conceptualized in specific subject domains in order for educators to efficiently help learners succeed in learning meaningful knowledge and skills.

The MDL recognizes that learning is a progressive process that encompasses both cognitive and affective components (Alexander et al., 1995). Specifically, it is presumed that success in learning depends on the interactive effects of prior knowledge, interests, and learning strategies accrued during each of the acclimation, competency, and proficiency learning stages. At the acclimation stage, learners may have limited prior knowledge and rarely have a strong individual interest in the knowledge domain. Situational interest, then, functions as the primary motivator to attract learners to learning and bring out their continuous effort. At the competency stage, learners are beginning to master knowledge. Situational interest may be internalized as individual interest. Learning strategies are used more frequently than before to help construct and reconstruct knowledge and skill. At 
the proficiency stage, learners have developed a high level of knowledge in the subject and have become proficient in using learning strategies. Individual interest is the sole motivator for them.

The multidimensional, multistage MDL has been studied in classroom-based learning (Alexander et al., 1995; Alexander \& Murphy, 1999). The findings support the claim that the integration of the cognitive process with motivation is a dominant predictor of learning achievement. However, the MDL and its function in K-12 physical education have not been investigated. Few studies have been conducted in physical education to explore the interactions among prior knowledge, learning strategies, and interest-based motivation, although prior knowledge, learning strategies, and interest-based motivation have been studied separately in research (Chen \& Darst, 2001; Lee \& Solmon, 1992). To address the dearth of research in this area, the current study was conducted.

Using the MDL as the theoretical framework, this study was designed to examine the interrelated roles of knowledge, interests, and learning strategies on learning in a middle school volleyball unit. It is assumed that physical education is an institutionalized subject-matter domain. The most important subject-matter knowledge that learners need to acquire includes information about human movement patterns, skills, and skill themes (Allison, Pissanos, Turner, \& Law, 2000) and health-related knowledge of physical activity (Corbin \& Lindsey, 1997). The content should be sequenced for K-12 learners for them to understand and appreciate complex functions and benefits of specific movement forms such as dance, team and individual sports, and fitness activities (National Association of Sport and Physical Education [NASPE], 2004). Also, physical education is a discipline with unique content specificity. Not only are learners expected to acquire knowledge and skills, but also to learn in a physically active manner (Arnold, 1979). In a learning-oriented curriculum where the goals and learning objectives are clearly defined, the physical activities have clear learning purposes. Students' physical engagement is for facilitating their learning. It is recommended that the physical engagement level in class should be taken into consideration when we examine the learning process in physical education.

The study was designed to address the following specific questions: a) What were the interrelations among knowledge, learning strategies, interests, physical engagement, and learning outcomes for middle school students in a volleyball unit? and b) Guided by the MDL, to what extent could the learning process be modeled in terms of the interrelations among knowledge, learning strategies, and interests?

In this study, learning outcomes were operationalized as the degree to which learners' knowledge, skill, and individual interest changed as a result of learning. Because there were only five class times in this specific volleyball unit, we speculated that the learners did not have enough time to practice volleyball skills to an extent that improvement could be assessed with valid and reliable skill tests (Tritschler, 2000). In this study, students' skill improvement was not measured. This limitation should be addressed in future studies.

A hypothesized model, as described in Figure 1, has been developed to present hypothesized relationships. In the model, prior knowledge was hypothesized to be positively associated with prior individual interest. It was also hypothesized that the interactions of prior knowledge and individual interest with situational interest would influence learners' application of learning strategies. Situational 


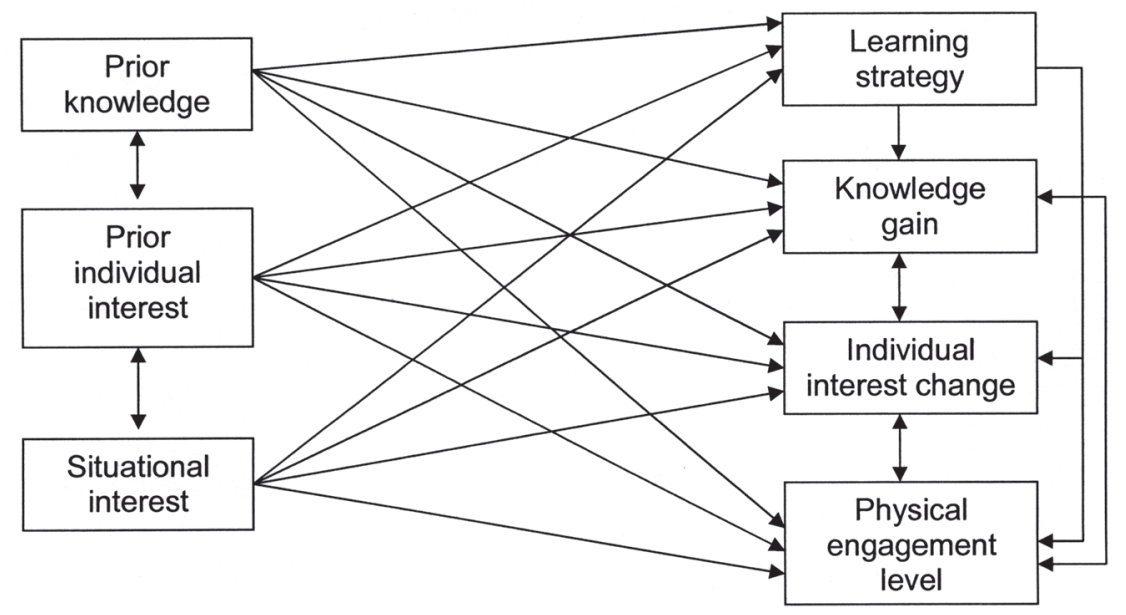

Figure 1-The hypothetical model of learning in physical education.

interest, which is often stimulated by environmental factors, was hypothesized to contribute to the development of individual interest. The interactions among prior knowledge, prior individual interest, situational interest, and learning strategies were hypothesized to influence knowledge gain and individual interest change. In addition, prior individual interest, situational interest, and their interactions might influence physical engagement level, which, in turn, might be associated with the individual interest change.

\section{Methods}

\section{Participants and Setting}

The study was conducted in one middle school chosen from a pool of typical suburban middle schools in the metropolitan Washington-Baltimore area. Besides student demographic representativeness, two criteria were used to establish the pool of schools: a) the physical education curriculum should be in line with both national and state standards, and b) physical education teachers used measurable means to assess students' skill and knowledge outcomes in each unit.

There were 804 students from sixth grade to eighth grade in the school. Students in this school came from low to middle class backgrounds, with $23 \%$ receiving assisted meal benefits. The student body consisted of $70.6 \%$ Caucasian, $22.4 \%$ African-American, 3.5\% Hispanic-American, and 3.5\% Asian-American.

The participants in this study were sixth-grade students $(\mathrm{N}=91)$. They were chosen to alleviate possible confounding between prior knowledge and graderelated learning content. As first-year middle school students, the participants were experiencing a physical education curriculum that was different from what they had in elementary school. In addition, sixth-grade students have acquired an 
initial understanding of the value of using learning strategies and are capable of expressing their thinking clearly (Paris \& Lindauer, 1982). They begin to actively use strategies to guide their learning behavior.

Because of incomplete data, 11 participants were eliminated from the final data analyses. The final sample consisted of 80 students ( 43 boys, 37 girls). There were $60(75 \%)$ Caucasians, $12(15 \%)$ African-Americans, $4(5 \%)$ Asian-Americans, and $4(5 \%)$ Hispanic-Americans. Parental consent forms and student assent forms were received prior to data collection.

A 90-minute rotating block schedule was used in this school. There were four periods in a school day. The first period was designated for classroom learning. Physical education was scheduled in the subsequent three periods. According to the school's A-day, B-day, or C-day schedule, students had a physical education class in every third day throughout the school year.

One female and two male full-time certified physical education teachers taught physical education in this school. Their teaching experiences ranged from 5 to 25 years. They were all active American Alliance for Health, Physical Education, Recreation, and Dance (AAHPERD) members. The school was a state physical education demonstration school with a reputation for providing quality programs consistent with national and state standards.

Volleyball was chosen as the content for the study because of its popularity in the middle school physical education curriculum in this area, according to the county's physical education curriculum guide. The study of volleyball is likely to have a profound implication for teaching and learning in middle school physical education. The volleyball unit was team-taught, with the female teacher as the lead teacher. She had been teaching middle school physical education for 25 years and was a recipient of the Teacher of the Year Award from NASPE. The unit was taught as a new content, with the emphasis on basic skills (e.g., forearm pass, overhand pass, and underhand serve), rules, and terminology (e.g., side out, scoring, game/ match, position rotation, front-court restrictions). The concepts and skills were learned through skill practices in groups and modified (simplified) games. The teachers used the direct and problem-solving methods. Concept-based information, such as skill cues, was frequently emphasized during teaching.

\section{Variables and Measures}

Knowledge Measure. Students' knowledge in volleyball was assessed using a 14-item multiple-choice test designed for the current study. All items on this test represented content chosen from the county's physical education curriculum guide for sixth graders. The purpose of this test was to gauge students' cognitive understanding of volleyball.

In order to examine the content validity of the knowledge test, five experienced physical education teachers (with 10 to 25 years' experience teaching volleyball) were asked to rate each question in terms of its content accuracy and difficulty appropriateness for sixth-grade learners $(1=$ very inaccurate/inappropriate, $6=$ very accurate/appropriate). Based on the rating, all items scored above 4.5 in average, suggesting that the test has an acceptable content validity. The internal consistency coefficient (Cronbach's $\alpha$ ) for the measure at pretest was .66. We considered this 
to be an acceptable level of reliability, given the relatively low variability of scores $(M=6.32, S D=1.59)$.

Individual Interest. Individual interest in volleyball was measured using the Physical Activity Interest Survey (Chen \& Darst, 2002). The instrument asks learners to rate their interest in various physical activities on a 7-point Likert-type scale $(7=$ highest interest, $1=$ lowest interest $)$. To avoid self-referencing in rating, the instrument asks the respondent to identify an activity (any activity in school or at home) he or she is most interested in and give a rating score of 7 . Then the respondent is instructed to use the activity as a reference to compare and rate other activities. According to Tobias (1994), this measurement context may prevent individual respondents from interpreting the rating scale inconsistently; thus, the internal validity of the measure can be better maintained. The survey in this study included 18 physical activities offered in the physical education curriculum.

Situational Interest. Situational interest was measured using a 24-item Situational Interest Scale (Chen, Darst, \& Pangrazi, 1999). Items representing situational interest and its source dimensions (Novelty, Challenge, Attention Demand, Exploration Intention, and Instant Enjoyment) are rated on a 5-point scale (5 = strongly agree, 1 = strongly disagree) in terms of specific learning tasks the learner is experiencing.

The construct validity of Situational Interest Scale has been reported in Chen et al.'s (1999) study. The internal consistency coefficients (Cronbach's $\alpha$ ) were .78, $.80, .90, .91, .90$, and .95 for Novelty, Challenge, Attention Demand, Exploration Intention, Instant Enjoyment, and Total Interest subscales, respectively, indicating that the Situational Interest Scale can generate valid and reliable data.

Learning Strategies. Learning strategies were measured using the Cognitive Process Questionnaire in Physical Education (CPQPE) (Solmon \& Lee, 1997). In this questionnaire, learners' confidence-efficacy, attention-concentration, willingness to engage, and use of learning strategies are measured using 32 items. Each item asks learners to identify themselves with a described learning behavior and to rate it on a 5-point scale with 1 meaning "not like me at all" and 5 meaning "very much like me."

Solmon and Lee (1997) reported internal consistency coefficients (Cronbach's $\alpha$ ) of .75, .79, .72, and .66 for confidence-efficacy, attention-concentration, willingness to engage, and strategies subscales, respectively. For this study, the measures of cognitive process dimensions other than learning strategy were of little relevance. Only the learning strategy subscale was used to represent the learners' strategy application during learning.

Physical Engagement. In-class physical engagement level was measured using Yamax SW-200 Digi-Walker pedometers (Tokyo, Japan) that recorded total steps taken during a lesson. Under the fixed length of class time, the number of steps would reflect students' physical engagement level in the class (Shen, Chen, Scrabis, $\&$ Tolley, 2003). The validity of the Digi-Walker has been demonstrated in clinical research (Bassett et al., 1996) and field-based research (Chen \& Shen, 2004). In addition, in order to maintain the accuracy of the measure, all Digi-Walker 
pedometers were checked using a walking test and a manual shake test (Vincent $\&$ Sidman, 2003) prior to data collection.

Learning Outcomes. The residual gain scores in knowledge and individual interest for each student were used to represent the learner's knowledge gain and individual interest change in order to avoid the influence of pretest on the result (ceiling effect). The residual gain scores were computed using a linear regression model in which the pretest was the predictor and the posttest was the criterion.

\section{Data Collection}

The researchers and trained graduate students collected all the data during regular physical education classes. During the process, the researchers were responsible for distributing and collecting the survey instruments, answering questions, and collecting pedometer data. The teachers taught the classes as they normally did and assisted in managing students' seating during the data collection process.

The pre-individual interest survey and knowledge test were administered at the beginning of a lesson before the volleyball unit began. During the lesson, students were also trained on how to use the pedometers correctly. Situational interest, learning strategy, and pedometer data were collected in three instruction lessons (as opposed to skill application or game lessons) that focused on understanding of concepts and development of basic skills. Before each lesson began, students put on and secured the pedometers to their waist bands and reset the step reading to zero. Immediately after the lesson, they removed the pedometers, recorded the number of steps on a recording sheet, and completed the Situational Interest Scale and Cognitive Processes Questionnaire. The researchers verified the recorded number of steps with the display on the pedometers while monitoring students who were independently completing the questionnaires. In the last lesson of the unit, the post-individual interest survey and the knowledge test were administered.

\section{Data Analysis}

In the preliminary analysis, all data were subject to accuracy screening, descriptive analyses, and a series of statistical assumption tests. Reliability of the questionnaire data was examined using Cronbach's approach for internal consistency. The scores of situational interest and learning strategies from the three lessons were aggregated and averaged for subsequent analyses.

Pearson product-moment correlations were conducted to address the research question of general interrelations among knowledge, interests, learning strategies, physical engagement, and learning outcomes. Further, the strength of the interrelations observed in the data was used to warrant testing of the MDL model. To address the research question of testing the MDL model, a path analysis was conducted to map out the meaningfulness of the interrelations among the variables.

\section{Results}

The reliability of the questionnaire data was examined using Cronbach's approach. The internal consistency coefficients (Cronbach's $\alpha$ ) were .73 for the 
learning strategy data and .87 for the situational interest data, indicating acceptable reliability for these measures. The descriptive statistics for each measure are reported in Table 1 . All scores were normally distributed (skewness indices ranging between -.787 and .768).

\section{Correlation Analysis}

Results of the correlation analyses were reported in Table 2. In concert with the predictions of the MDL, a weak but significant correlation was found between knowledge and individual interest in pretest $(r=.32, p<.05)$. Also, negative correlations were found between prior knowledge and knowledge gain $(r=-.43$, $p<.01)$ and between prior individual interest and individual interest change $(r=-.26, p<.05)$. There was a moderate correlation between learners' knowledge gain and individual interest change $(r=.39, p<.01)$. Prior individual interest was correlated with situational interest $(r=.30, p<.05)$. However, prior knowledge was not correlated with either situational interest or learning strategy. A moderate correlation was found between learning strategy and situational interest $(r=.49$, $p<.01)$. There was a moderate correlation $(r=.48, p<.01)$ between situational interest and steps taken in the class. But neither situational interest nor learning strategy was associated with knowledge gain.

\section{Path Analysis}

The path model analysis was conducted to address the extent to which learning in volleyball could be modeled in relation to prior knowledge, learning strategies, and interests. Path analysis was selected because it is the most direct modeling approach with an omnibus algorithm (Loehlin, 1998), and can address the hypothesized relations among variables at different points in learners' academic

Table 1 Descriptives for Knowledge, Interests, Learning Strategies, Steps, Knowledge Gain, and Individual Interest Change

\begin{tabular}{lccc}
\hline Variable & Maximum & Mean & $\begin{array}{c}\text { Standard } \\
\text { deviation }\end{array}$ \\
\hline Pre-individual interest & 7 & 4.36 & 1.63 \\
Pre-knowledge & 14 & 6.32 & 1.59 \\
Learning strategy & 25 & 15.55 & 4.43 \\
Situational interest & 20 & 15.30 & 3.89 \\
Steps & - & 31.43 & 6.03 \\
Post-knowledge & 14 & 11.01 & 2.04 \\
Post-individual interest & 7 & 4.87 & 1.29 \\
\hline
\end{tabular}




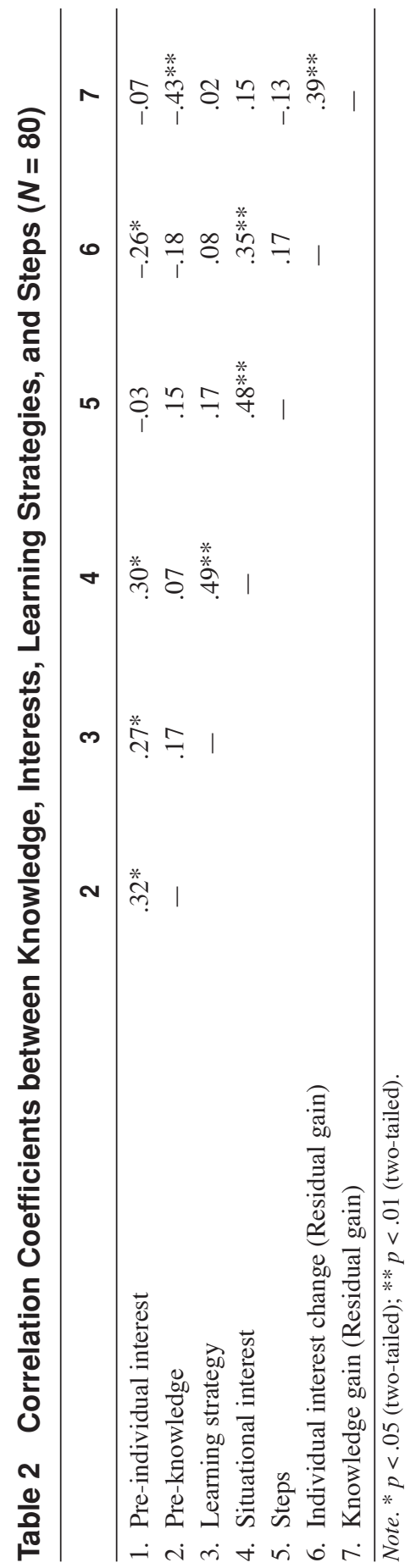


development. Also, in studies with a relatively small sample size, such as that in this study, path analysis is a good choice for effective data analysis.

Given the concern about the influence of small sample size on result estimates, we elected to use several conservative model-data-fit values to diminish the bias in the analysis (Hu \& Bentler, 1999). They include the ratio of $\chi^{2}$ to the degree of freedom $\left(\chi^{2} / d f \leq 1.96\right)$ to evaluate the overall fit of the model and the influences of the individual pathways, the Comparative Fit Index (CFI > .95) to evaluate the model's absolute or parsimonious fit relative to the null or hypothetical model, the Standardized Root Mean Squared Residual (SRMR < .10) to evaluate the model data fit by estimating the overall discrepancy between observed and model-implied covariances, and the Root Mean Square Error of Approximation $(\mathrm{RMSEA}<.10)$ to estimate the difference between the hypothesized covariance matrix and actual sample covariance matrix.

We conducted a path analysis based on the rationale of the "model generating" (MG) (Jöreskog, 1993, p. 295) approach rather than an alternative modeling (AM) approach because there are no other similar models parallel to or competing with the MDL that incorporate interests, domain-specific knowledge, and learning strategies together for empirical examination in physical education. Specifically, a two-step procedure, model construction and model modification, was followed in this study. In the analysis, a tentative initial model based on theoretical articulation was constructed first. If the model did not fit the data, the model should be modified and tested again using the same data in terms of the model adjustment information derived from the model algorithm, such as the Lagrange multiplier (LM) test and Wald's test (Kline, 1998). The goal of the test was to find a model that "not only fits the data well from a statistical point of view but also has the property that every parameter of the model can be given a substantively meaningful interpretation" (Jöreskog, 1993, p. 295).

It is worthwhile to notice that the initial theoretical model depicted in Figure 1 had not been proposed and tested in a physical education setting. Therefore it was highly tentative and hypothetical. The purpose of using path analysis was to examine this particular model. This analysis environment and the relatively small sample size should be taken into account when we attempt to make further inferences.

The first path analysis was based exclusively on the hypothetical model of MDL. In this hypothesized model (see Figure 1), single-headed arrows with solid lines represent direct effects and double-headed arrows represent covarying relationships between the variables, indicating a possible mutual and interactive influence between the variables. The initial analysis showed that the hypothesized model was almost saturated with perfect goodness-of-fit indices $\left(\chi^{2}=.00 ; \mathrm{CFI}=\right.$ $1.00)$ and few degrees of freedom, indicating that the model should be modified (Jöreskog \& Sörbom, 1993).

From this invalid model, however, it appears that pre-individual interest and knowledge contributed highly to interest change and knowledge gain, while situational interest seemed to have an important role in determining learning strategy and individual interest change. The information from this initial analysis made it necessary to modify the hypothetical model to better explain the relationships among variables.

Based on theoretical meaningfulness and the results of the Lagrange multiplier test and Wald's test (Kline, 1998), adjustments were made to re-specify the model. 
Consistent with the statement that simple behavioral indicators may not reflect the complexity of the learning profile during the learning process (Alexander, 1997), the pathways from prior knowledge, individual interest, and learning strategies to steps were excluded. Figure 2 presents a modified model with a good fit to the data $\left(\chi^{2} / d f=\right.$ $1.68 ; \mathrm{CFI}=.96 ; \mathrm{SRMR}=.06 ; \mathrm{RMSEA}=.08)$. To examine the statistical significance of each individual path in order to estimate the meaningfulness of the path between two variables, the $z$ statistic was used because of its robustness for multivariate normal data (Bollen, 1987). A $z$ statistic is obtained by using the unstandardized path coefficient divided by its standard error. Thus, at an alpha level of .05 , the $z$ would need to be greater than \pm 1.96 so that the magnitude of the path coefficient can be considered to differ from zero with statistical significance. In other words, a $z \geq[2]$ indicates that an individual path is meaningful in interpreting the particular directional relationship between the two variables.

In terms of $z$ statistics, it was found that learning strategies and steps were mainly accounted for by situational interest. Besides the influence from preindividual interest, learners' individual interest change was also influenced by situational interest. However, pre-knowledge did not contribute to learning strategies and the influence of learning strategies on knowledge gain was weak $(r=.02, z=.21)$.

We further adjusted the model to examine the relationship between steps and individual interest change and knowledge gain. We assumed that learners' high active participation in learning activities would lead to high knowledge and interest acquisition. However, a fit model $\left(\chi^{2} / d f=1.66\right.$; CFI $=.95$; SRMR $=.07$; RMSEA $=.09$ ), shown in Figure 3, confirmed the result from the correlational analysis

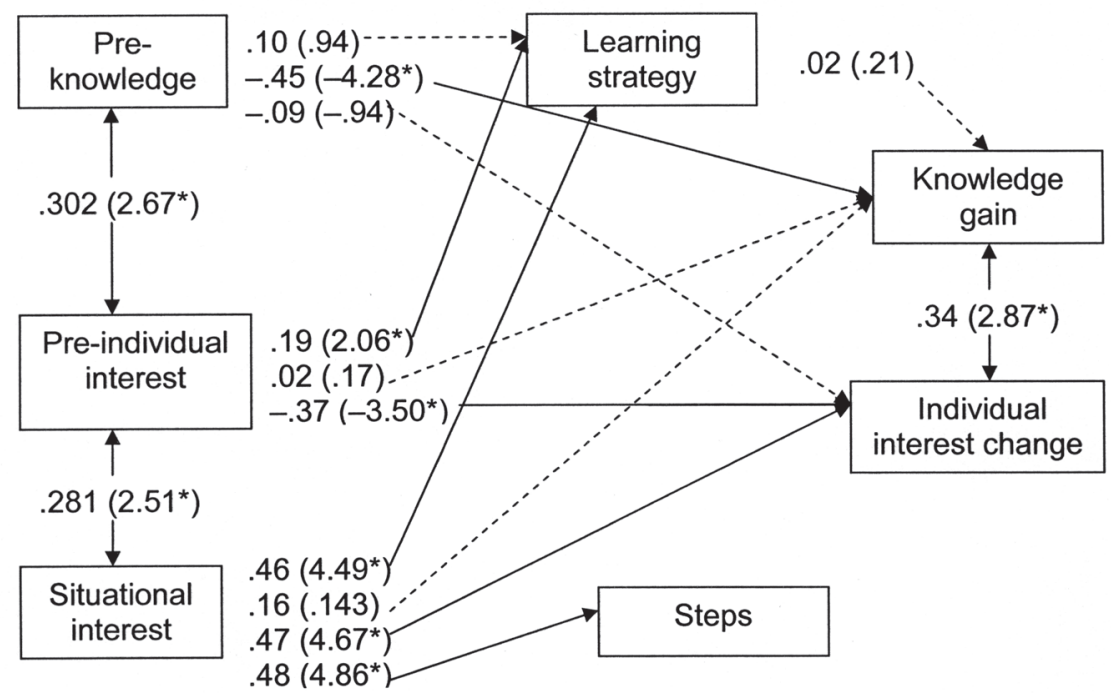

Figure 2-Modified model of learning in volleyball (1).

Note. The numbers outside the parentheses are path coefficients; the numbers within the parentheses are $z$ statistics. $* p<.05$. 


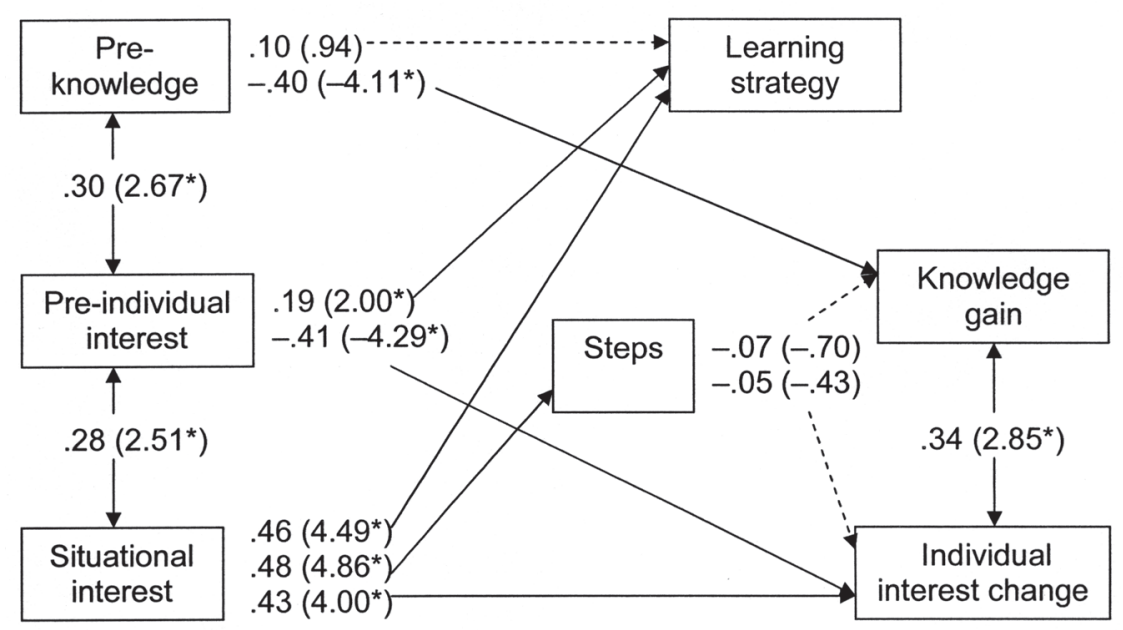

Figure 3-Modified model of learning in volleyball (2).

Note. A dashed arrow denotes an invalid path. The numbers outside the parentheses are path coefficients; the numbers within the parentheses are $z$ statistics. ${ }^{*} p<.05$.

that steps did not have directionally significant pathways leading to knowledge and interest acquisition, indicating that physical engagement level in class did not contribute to students' knowledge and individual interest achievement.

\section{Discussion}

The purpose of the study was to explore the interrelations among prior knowledge, learning strategies, interests, physical engagement, and learning outcomes in middle school physical education. The MDL (Alexander et al., 1995) was used as the theoretical framework to guide this research. The framework postulates that learning in a specific knowledge domain is a dynamic and interactive process influenced by prior knowledge, interests, and learning strategies. In this preliminary study, physical education learners' interests, knowledge, and learning strategies were measured and the interrelations among them were analyzed in an attempt to support the MDL.

\section{Function of Prior Knowledge and Individual Interest}

Although the MDL, an overarching theoretical model for human learning, describes learning as a progressive process from acclimation to competence to proficiency, it is reasonable to assume that K-12 learners have not achieved at the proficiency level in any subject matter domains that are being taught to them 
(Alexander, 1997). A similar assumption can be made for the learners in this study, where the participants could be considered to be at either acclimation or early competence levels in learning volleyball. This assumption was supported by the prior knowledge test scores. The mean score of 6.32 out of 14 reflects their limited prior knowledge of volleyball.

According to the MDL, individual interest can directly influence the learning process. The function of individual interest in learning can be manifested in the application of learning strategies and cognizance of situational interest (Alexander et al., 1995). Individual interest often guides the application of learning strategies (Alao \& Guthrie, 1999). The significant path coefficient from individual interest to learning strategies suggests that learners who were interested in the content were more likely to use learning strategies to understand the concepts than those who were not interested in the content. Their cognitive involvement during learning was effortful as the result of high individual interest (Alexander et al., 1995).

In physical education, learners with high individual interest in an activity may be more cognizant about situational interest and its effect than those with low individual interest (Chen \& Darst, 2002). They often view the activity as more interesting and attractive. The correlation analysis revealed a weak but significant correlation between prior individual interest and situational interest. Further, the results from the path analysis indicate that the learners' individual interest was interactive with the motivational effect of situational interest. The evidence may suggest that the learners' high individual interest helps enhance the motivation effect of situational interest associated with learning tasks.

It is suggested that rich prior knowledge may lead to successful use of learning strategies (Alexander et al., 1995). A strong relationship between individuals' prior knowledge and successful use of strategies has been observed in academic learning (Murphy \& Alexander, 2002) and physical education (Lee et al., 1992). However, this relationship is not evident in this study. Based on the path analysis, the direct influence of prior knowledge on the application of learning strategies was not found. The result indicates that the influence of prior knowledge on the application of learning strategies was indirect in this learning environment. The function of prior knowledge on learning strategies might need the individual interest as a mediator to transfer.

Learning in a specific domain should result in the enhancement of knowledge and individual interest (Alexander et al., 1995). In physical education, learning should yield valued learning outcomes (Ennis, 1998). During learning, prior knowledge can serve as a scaffold for new knowledge to build on. Individual interest, which is developed over time during the learner's constant and consistent interaction with a certain activity in a particular environment (Krapp, 1999), can improve the learner's information storage, enhance understanding, and increase the quality of learning.

Descriptively, comparing the scores from the pretest with those from the posttest revealed that the learners, as a group, did gain additional knowledge in volleyball. A small but positive change was observed in their individual interest as well. Correlationally, however, the knowledge gain and individual interest change were found negatively correlated with prior knowledge and individual interest. The learners with higher prior knowledge and individual interest gained less on both variables than those with lower prior knowledge and individual interest. 
It may be speculated that the smaller knowledge gain in learners with higher prior knowledge results from the nature of volleyball and the instruction objectives of the unit. In this introductory unit for beginners, the teachers placed curricular and instructional focus on helping the learners at the acclimation stage. Those learners with higher prior knowledge might not be given enough opportunity to construct their knowledge and skills appropriate to their prior knowledge and individual interest. Also, it is possible that the measurements used in the study led to the results. The knowledge gain was based on pre- and posttest results of a paper-pencil knowledge assessment rather than skill-application assessments that require the learners to actually apply their declarative knowledge in procedural forms.

In this study, learners' physical engagement level was considered as a facilitator of learning. It was hypothesized that learners' prior knowledge and individual interest might associate with their physical engagement level. However, the hypothesized relationships are absent in the data. The weak correlations of steps with prior knowledge and individual interest suggest that learners' physical engagement did not relate to their prior knowledge and interest. The results of the Lagrange multiplier test and Wald's test (Kline, 1998) for model modification also suggest that it was not necessary to further examine the relationship in the path model, because of the low path coefficient. The finding seems to support the notion that the influence of prior knowledge and individual interest on learning behavior may not be reflected in the physical engagement level (Silverman et al., 1998). A systematic observation study on learners' learning behavior, such as quality and efficiency of learning practice in the class, is needed for further understanding this issue.

\section{Role of Situational Interest and Learning Strategies}

Situational interest, which results from the recognition of appealing features associated with a specific learning task (Mitchell, 1993), can be a significant and viable motivator to facilitate new knowledge learning (Hidi, 2000). In physical education, situational interest derives from appealing characteristics of learning tasks such as novelty, cognitive/physical challenge, attention demand, opportunities to explore, and instant enjoyment (Chen \& Darst, 2001). A high level of situational interest is considered necessary to lead the learner to a high degree of attention and mental readiness for achievement (Krapp, 1999) and may directly contribute to learners' physical involvement (Shen et al., 2003).

The moderate correlation between situational interest and the learning strategies suggests that the situational interest related to the application of learning strategies. The path analysis results lent additional support by revealing a direct, significant influence of situational interest on the learners' application of learning strategies. It can be suggested that situational interest is associated with the learners' cognitive efforts during the learning process (Alexander et al., 1995).

Moreover, the path analysis revealed that the association between situational interest and the application of learning strategies was independent of prior individual interest. In other words, after individual interest was controlled (co-varied), there still was a significant impact of situational interest on the application of learning strategies. It can be reasoned that learners' situational interest has an independent role in their cognitive learning. In a highly situationally interesting 
learning environment, situational interest may override the unmotivational effect of low individual interest during learning, and play an important role in learners' cognitive involvement (Shen et al., 2003).

As hypothesized in the MDL, when learners progress from the acclimation stage, situational interest can be internalized into individual interest to facilitate long-lasting learning (Alexander et al., 1995). A highly situationally interesting learning environment is expected to "catch" and "hold" learners' individual interest (Mitchell, 1993). In this study, the hypothesis was supported by the path analysis. The significant path coefficient from situational interest to individual interest change over the course of the unit suggests that situational interest had a strong impact on the enhancement of individual interest. Speculatively, the results show a possibility that situational interest can be internalized into individual interest for acclimated learners.

In physical education, learners' situational interest can directly associate with their physical engagement (Shen et al., 2003). When learning tasks possess high situational interest, learners are likely to become involved in the activity (Chen $\&$ Darst, 2001). In this study, this assumption was confirmed with the significant path coefficients from situational interest to physical engagement level. It seems that high situational interest did influence their physical involvement. The result replicated the findings from a previous study (Shen et al., 2003).

Appropriate learning strategies enhance learning. Learning strategies can help learners capture and organize information efficiently and enhance their ability to understand and remember the content (Armbruster, 2000). It is expected that application of learning strategies is associated with learning outcomes in learning volleyball. However, the data did not provide convincing evidence for this association. A weak path coefficient from learning strategies to knowledge gain was found in the model.

We attributed this result to the specific learning context in this study. As Solmon and Lee (1996) argued, the role of learning strategy might depend upon the level of difficulty in the learning task. When the content does not provide optimal challenge, learning strategies may not be applied and used well during learning. As new content for beginning middle school students, the learning tasks in the volleyball unit were considered to be introductory in nature. The learners' ratings on application of strategies reflected that their use of learning strategies was not at a high level.

\section{Learning Progression}

Learning in a particular knowledge domain can be characterized as a progression from an acclimated or naïve stage. According to the MDL, learning progression is dependent on the level of involvement and interrelations of knowledge, individual interest, and learning strategies (Alexander et al., 1995). Learning progression is characterized by interactive, cohesive change observed in all the variables rather than an isolated one. In other words, positive changes should be manifested in knowledge and individual interest as a result of their dynamic interaction.

In this study, knowledge gain and individual interest change were indicators of learning progression as specified in the MDL theory. The moderate correlation between knowledge gain and individual interest change suggests that students' 
knowledge gain and individual interest development indeed occurred simultaneously as described in the MDL. In addition, the changes may serve as evidence of the relevance of the MDL theory in interpreting the learning in physical education as a holistic process influenced by prior knowledge, motivation, and learning strategies.

In physical education, learners are expected to be not only cognitively engaged in the learning process, but also physically active, to facilitate knowledge acquisition and to receive health benefits of physical activities (NASPE, 2004). It is difficult to find a balanced instruction to provide learners with opportunities to learn useful movement and/or physical activity concepts and principles and to be physically active at a moderate or rigorous intensity level in the short time allocated for physical education in schools (McKenzie \& Sallis, 1996). The very weak path coefficient from steps to knowledge gain seems to echo the argument.

\section{Conclusion}

This study provides empirical evidence of complex interactions among the cognitive and affective factors in physical education. It is apparent that knowledge, interests, and learning strategies interactively contributed to the learners' knowledge gain and individual interest change. The simultaneous growth of knowledge and individual interest further supports the notion that learning in physical education is a holistic, progressive process (Jewett, Bain, \& Ennis, 1995).

However, although the study yielded useful information, the MDL was only tested within one topic knowledge area, volleyball. As discussed above, some theorized interrelations were absent or unexpectedly weak in the data. The reader must interpret the results with great caution and take into account the uniqueness of the study context. Future studies with different learning areas and participants are needed to further examine the tenability of the MDL theory in physical education.

\section{References}

Alao, S., \& Guthrie, J.T. (1999). Predicting conceptual understanding with cognitive and motivational variables. The Journal of Educational Research, 92, 243-253.

Alexander, P.A. (1997). Mapping the multidimensional nature of domain learning: The interplay of cognitive, motivational, and strategic forces. In M.L. Maehr \& P.R. Pintrich (Eds.), Advances in motivation and achievement (Vol. 10, pp. 213-250). Greenwich, CT: JAI Press.

Alexander, P.A., Jetton, T.L., \& Kulikowich, J.M. (1995). Interrelationship of knowledge, interest, and recall: Assessing a model of domain learning. Journal of Educational Psychology, 87, 559-575.

Alexander, P.A., \& Murphy, P.K. (1999). Nurturing the seeds of transfer: A domain-specific perspective. International Journal of Educational Research, 31, 561-576.

Allison, P.C., Pissanos, B.W., Turner, A.P., \& Law, D.R. (2000). Preservice physical educators' epistemologies of skillfulness. Journal of Teaching in Physical Education, 19, 141-161.

Armbruster, B.B. (2000). Taking notes from lectures. In R.F. Flippo \& D.C. Caverly (Eds.), Handbook of college reading and study strategy research (pp. 175-199). Mahwah, NJ: Lawrence Erlbaum Associates. 
Arnold, P. J. (1979). Meaning in movement: Sport and physical education. London: Heinemann.

Bassett, D.R.J., Ainsworth, B.E., Leggett, S.R., Mathien, C.A., Main, J.A., Hunter, D.C., et al. (1996). Accuracy of five electronic pedometers for measuring distance walked. Medicine \& Science in Sport and Exercise, 28, 1071-1077.

Bollen, K.A. (1987). Structural equations with latent variables. New York: Wiley.

Chen, A., \& Darst, P.W. (2001). Situational interest in physical education: A function of learning task design. Research Quarterly for Exercise and Sport, 72, 150-164.

Chen, A., \& Darst, P.W. (2002). Individual and situational interest: The role of gender and skill. Contemporary Educational Psychology, 27, 250-269.

Chen, A., Darst, P.W., \& Pangrazi, R.P. (1999). What constitutes situational interest? Validating a construct in physical education. Measurement in Physical Education and Exercise Science, 3, 157-180.

Chen, A., \& Ennis, C.D. (2004). Searching for optimal motivators: Goals, interests, and learning in physical education [Monograph: Contemporary Issues on Motivation]. The Journal of Educational Research, 97(6), 329-338.

Chen, A., \& Shen, B. (2004). A web of achieving in physical education: Goals, interest, outside-school activity and learning. Learning and Individual Differences, 14, 169-182.

Corbin, C.B. \& Lindsey, R. (1997). Fitness and wellness. Madison, WI: Brown \& Benchmark.

Doyle, W. (1977). Paradigms for research on teacher effectiveness. Reviews of Research in Education, 5, 163-198.

Ennis, C.D. (1998). Shared expectations: Creating a joint vision for urban schools. In J. Brophy (Ed.), Advances in research on teaching (Vol. 7, pp. 151-182). New York: JAI Press.

Hidi, S. (2000). An interest researcher's perspective: The effects of intrinsic and extrinsic factors on motivation. In C. Sansone \& J.M. Harackiewicz (Eds.), Intrinsic and extrinsic motivation: The search for optimal motivation and performance (pp. 309-339). San Diego, CA: Academic Press.

Hu, L., \& Bentler, P.M. (1999). Cutoff criteria for fit indexes in covariance structure analysis: Conventional criteria versus new alternatives. Structural Equation Modeling: A Multidisciplinary Journal, 6, 1-55.

Jöreskog, K.G. (1993). Testing structural equation models. In K.A. Bollen \& J.S. Long (Eds.), Testing structural equation models. Newbury Park, CA: Sage.

Jöreskog, K.G., \& Sörbom, D. (1993). LISREL 8®: Structural equation modeling with the SIMPLISTM command language. Hillsdale, NJ: LEA.

Jewett, A.E., Bain, L.L., \& Ennis, C.D. (1995). The curriculum process in physical education. Madison, WI: Brown \& Benchmark.

Kline, R.B. (1998). Principles and practice of structure equation modeling. New York: Guilford Press.

Krapp, A. (1999). Interest, motivation, and learning: An educational-psychological perspective. European Journal of Psychology of Education, XIV, 23-40.

Lee, A.M. (1997). Contributions of research on student thinking in physical education. Journal of Teaching in Physical Education, 16, 262-277.

Lee, A.M., Landin, D.K., \& Carter, J.A. (1992). Student thoughts during tennis instruction. Journal of Teaching in Physical Education, 11, 256-267.

Lee, A.M., \& Solmon, M.A. (1992). Cognitive conceptions of teaching motor skill. Quest, 44, 57-71.

Loehlin, J.C. (1998). Latent Variable Models (3rd ed.). Hillsdale, NJ: Lawrence Erlbaum Associates, Publishers.

McKenzie, T.L., \& Sallis, J.F. (1996). Physical activity, fitness, and health-related physical education. In S.J. Silverman \& C.D. Ennis (Eds.), Student learning in physical education (pp. 223-246). Champaign, IL: Human Kinetics. 
Mitchell, M. (1993). Situational interest: Its multifaceted structure in the secondary school mathematics classroom. Journal of Educational Psychology, 85, 424-436.

Murphy, P.K., \& Alexander, P.A. (2002). What counts? The predictive powers of subjectmatter knowledge, strategic processing, and interest in domain-specific performance. The Journal of Experimental Education, 70, 197-214.

National Association for Sport and Physical Education [NASPE]. (2004). Moving into the future: National standards for physical education (2nd ed.). Reston, VA: Author.

Paris, S.G., \& Lindauer, B.K. (1982). The development of cognitive skills during childhood. In B. Wolman (Ed.), Handbook of developmental psychology. Englewood Cliffs, NJ: Prentice-Hall.

Pintrich, P.R., Marx, R.W., \& Boyle, R.A. (1993). Beyond cold conceptual change: The role of motivational beliefs and classroom contextual factors in the process of conceptual change. Review of Educational Research, 63, 167-199.

Renninger, K.A. (2000). Individual interest and its implications for understanding intrinsic motivation. In C. Sansone \& J.M. Harackiewicz (Eds.), Intrinsic and extrinsic motivation: The search for optimal motivation and performance (pp. 373-404). San Diego, CA: Academic Press.

Shen, B., Chen, A., Scrabis, K.A., \& Tolley, H. (2003). Gender and interest-based motivation in learning dance. Journal of Teaching in Physical Education, 22, 396-410.

Shuell, T.J. (1986). Cognitive conceptions of learning. Review of Educational Research, 56, 411-436.

Silverman, S., Subramaniam, P., \& Woods, A.M. (1998). Task structures, student practice, and skill in physical education. The Journal of Educational Research, 91, 298-306.

Solmon, M.A., \& Lee, A.M. (1996). Entry characteristics, practice variables, and cognition: Student mediation of instruction. Journal of Teaching in Physical Education, 15, 136-150.

Solmon, M.A., \& Lee, A.M. (1997). Development of an instrument to assess cognitive processes in physical education classes. Research Quarterly for Exercise and Sport, 68, 152-160.

Tobias, S. (1994). Interest, prior knowledge, and learning. Review of Educational Research, 64, 37-54.

Tritschler, K. (2000). Barrow \& McGee's practical measurement and assessment. Baltimore, MD: Lippincott Williams \& Wilkins.

Vincent, S.D., \& Sidman, C.L. (2003). Determining measurement error in digital pedometers. Measurement in Physical Education and Exercise Science, 7(1), 19-24. 